\title{
Justice and Feelings: Toward a New Era in Justice Research
}

\author{
David De Cremer ${ }^{1,3}$ and Kees van den Bos $^{2}$
}

In this special issue, the relationship between feelings and justice and its consequences are highlighted. Five articles discuss the role that affect, feelings, and emotions play in justice processes across a variety of social settings. In the present introductory article, the position of past and present justice research in relationship to these topics is briefly reviewed. In addition, reasons are outlined to show why a focus on these issues may be pivotal for a better understanding of social justice and how this may pave the way for a new, more process-oriented era in social justice research, focusing more on "hot" cognitive aspects as they pertain to social justice concerns.

KEY WORDS: justice; emotions; feelings; affect.

Justice is essential to our social functioning as is indicated by the fact that the concept of justice (as well as its violation) often dominates our daily experiences and discussions (e.g., Finkel, 2001; Folger, 1984). Indeed, people often talk about the good and bad things they encounter in their social interactions and frame them as instances of justice versus injustice. Instances of justice take a variety of forms and researchers have throughout the last few decades devoted much attention to distinguishing among different "types" of justice (e.g., Bies \& Moag, 1986; Greenberg \& Colquitt, 2005; Thibaut \& Walker, 1975). More precisely, justice involves issues of

\footnotetext{
${ }^{1}$ Department of Social Psychology, Tilburg University, P.O. Box 90153, 5000-LE Tilburg, The Netherlands.

${ }^{2}$ Utrecht University, Utrecht, The Netherlands.

${ }^{3}$ Address correspondence to: David De Cremer, Department of Social Psychology, Center of Justice and Social Decision Making, P.O. Box 90153, 5000-LE Tilburg, The Netherlands., e-mail: d.decremer@uvt.nl, www.centerofjust.com
} 
distribution, treatment, formal and informal decision-making procedures, and so forth. This variety of justice instances has been reflected in the scientific use of concepts such as distributive, procedural, and interactional justice. Concerns about social justice go back to ancient moral philosophers like Plato and Socrates (Rawls, 1971), so by now it is no surprise that we have accumulated an impressive amount of studies addressing a variety of justice issues (for reviews, see, e.g., Brockner \& Wiesenfeld, 1996; De Cremer \& Tyler, 2005; Folger \& Cropanzano, 1998; Greenberg \& Colquitt, 2005; Miller, 1999; Tyler \& Smith, 1998; Van den Bos \& Lind, 2002).

All these studies have shown that social justice reveals important consequences and that social psychological processes and factors play an important role. Indeed, the observation of justice concerns (as we encounter them in our daily experiences) has been shown to emerge also in more controlled laboratory settings, so that we are now in a position to focus more directly on the social psychological processes that explain why people direct attention to justice and how they use information about justice (Van den Bos, 2001). As such, research on social psychology is now in a position to demonstrate that social-cognitive and motivational processes underlie the formation of justice judgments and reactions toward justice versus injustice (De Cremer \& Tyler, 2005; Van den Bos \& Lind, 2002). Thus, it is clear that justice matters and that people care about justice for a variety of reasons (i.e., people may even defend the view that justice is omnipresent and that the pursuit of justice is in itself a guiding and moral directive in our social lives; Montada, 2003).

However, it is fair to note that by assuming that a justice motive is simply present, less attention is devoted to the initial psychological processes that determine whether people evaluate fairness or not, or, in other words, to the processes that make us understand why people evaluate instances of justice or injustice in the first place (Lerner, 2003). As noted earlier, social psychological research has shown that certain deliberative and motivational processes guide evaluations of justice, but, in our view this approach does not emphasize sufficiently that the issue of determining justice or injustice is often a matter of intuition and feeling. In making this claim, we thus agree with the view of emotion researchers that "openness to feelings is a useful and even necessary, adjunct to rationality and to effective social thinking (Damasio, 1994)" (Forgas, 2000, p. 1). In the present special issue, we focus our attention on the role that feelings play in the social psychology of justice. Feelings can be referred to as phenomenological states that have an affective or experiential dimension that is reflected in terms of the emotions that people feel (e.g., anger, sadness, joy, and so forth; see Watson, 2000).

Thus, one specific psychological seems to have been ignored in empirical justice research is the role of feelings. This observation is not new, as illustrated by a rapidly growing number of quotes by justice researchers stressing the importance of emotions. For example, with respect to the status 
of emotions in justice research, Weiss et al. (1999) argue that, "the relative lack of empirical research assessing emotional reactions to conditions of unfairness is a serious omission." (p. 786,), whereas Bies and Tripp (2002) note; "to understand justice in organizations, one must understand the events that arouse the sense of injustice - the emotions of injustice" (pp. 204-205). Moreover, with respect to the role that emotions play, Barclay et al. (2005, p. 629) very recently observed that, "although previous justice theories and research suggest emotions are part of the relationship between the experience of injustice and the tendency to retaliate ...little empirical research has examined the mediating role of emotion."

Although the worries of these researchers seems to indicate that more and more attention will be directed to the emotional basis of justice, it is disappointing to see that this subject does take a central role in theoretical accounts of justice, but that currently still few attempts are undertaken to translate researchers' conceptual thinking on justice and emotions into the practice of scientific studies. As we mentioned already, a closer focus on the relationship between emotions and justice seems warranted, particularly if one looks briefly at the history of human justice and morality.

Philosophers such as Aristotle and Hume already emphasized the role that emotions play in affecting deliberative processing of justice and morality issues in our social environment (e.g., Hume, 1739/1992; Lyons, 1999). These philosophical ideas have to be seen in the perspective of the debate about whether justice and morality have a rational or a more intuitive basis (e.g., Haidt, 2001; Kant, 1959). In those days, rationalists assumed that our ability to cognitively deliberate social information differentiates us from other species and makes us superior, also in a moral way. In this process, emotions were sometimes seen as having an undesirable influence on our cognitions and way of thinking about morality and justice. Nevertheless, the discussion about the valued role of emotions continued and was also picked up in the 20th century when Adams (1965), a management researcher, introduced equity theory. In this theory, it was explicitly acknowledged that people could feel anger and resentment when being awarded in an unfair and disadavantageous manner. Around the same time, the sociologist Homans (1961) also discussed the issue of distributing outcomes and rewards and emphasized the role of anger and guilt. Despite these references to emotional influences most justice research (that was stirred very much by the work of Adams) remained a focus on attitudinal and behavioral reactions. In the 1980s and 1990s the work of Bies (1987) showed that the sense of injustice led people to experience intense emotional states that one could not easily relieve, which Folger and Cropanzano (1998) referred to as moral outrage.

In the present special issue, we thus focus our attention on the role of the experience of emotions when it comes to issues of social justice. We hasten to add, however, that our promotion of a more emotional perspective 
on justice issues does not imply that cognition does not play a role. In fact, there is an abundance of evidence available in social psychology demonstrating that both cognition and affect often interact in predicting human behavior (Forgas, 2000) and justice judgments (Van den Bos, 2003). Also, evolutionary psychology sees both psychological components as interrelated as indicated by their idea that emotions are an important component of our cognitive architecture responsible for directing and guiding our actions (Cosmides \& Tooby, 1992). Thus, it is not our intention to claim that cognition does not play a role. On the contrary, we think that more processoriented research is needed in order to better understand how people form justice judgments (Van den Bos \& Lind, 2002), and hence we would applaud a special issue on the social-cognitive aspects of justice judgment processes as well. This said, we also think it is important to simultaneously stress several reasons why a focus on emotions and feelings is also needed.

First, because much justice research had (and still has) a strong focus on behavioral consequences (e.g., Brockner \& Wiesenfeld, 1996), it follows logically to include a focus on emotions. That is, prior justice research has shown that negative emotions instigate actions such as protest, revenge, absenteeism, and turnover (Bies \& Tripp, 2002; Griffin, O' Leary-Kelly, \& Collins, 1998; Skarlicki \& Folger, 1997). This effect of emotions on behavior has also been articulated in the affective events theory (Weiss \& Cropanzano, 1996) that argues that emotions can affect behavior directly (affect-driven actions) or indirectly (judgment-driven actions). Further, emotions are evaluative states although that are associated with some object, person, or event of relatively short duration (Frijda, 1993; Larsen, et al. 2002), they do have consequences for people's actions and behaviors, referred to as action tendencies (Izard, 1993). Thus, emotions are elicited by external situations and are subjectively experienced, leading people to determine whether the emotion has a positive or negative valence, how intense the emotion is (Russell, 1980), and which discrete form the emotion takes (e.g., anger or guilt; Lerner \& Keltner, 2000). Once the valence, intensity, and form of the discrete emotion are clarified, the experience is connected to a person or situation, which instigates actions (Frijda, 1993).

Second, as already suggested, justice is not only a judgment but can also represent an intuition or feeling. Indeed, often people's judgments of whether a decision or treatment is fair follows from how they feel about the social instance at hand; that is, they seem to experience justice first and then make up their mind about it (see also Haidt, 2001 for a similar line of reasoning with respect to the issue of morality). In a similar vein, Chebat and Slusarczyk (2005, p. 665) recently noted that "individuals do not calculate justice. They rather experience a justice-related emotion and react to their emotion." Thus, in line with these authors, we believe that identifying the role of emotions in justice can help us in highlighting the subjective and 
intuitive nature of justice judgments in general and in specific situations. In fact, instances of injustice may first activate some kind of "emotional deliberation" before judgments, decisions, and actions are given shape.

Third, as indicated earlier, discrete emotions such as anger and frustration are evoked by persons, situations, and other social events. The elicitation of these discrete emotions means that they help us to appraise or evaluate the situation at hand. Indeed, Lerner, Small, and Loewenstein (2004, p. 337) note that discrete emotions elicit specific appraisals that form "an implicit lens for interpreting subsequent situations." Thus, social situations and events receive meaning through this appraisal process. As a result, depending on the specific emotion evoked, situations can be seen as more versus less unfair. To date, not much attention has been given to emotionrelated influences on the justice judgment process (for some exceptions to this statement, see, e.g., De Cremer, 2006; Sinclair \& Mark, 1991, 1992; Van den Bos, 2003). Mikula et al. (1998, p. 771) also noted that "injustice or unfairness are rarely mentioned explicitly by appraisal theorists, whereas Ellsworth and Scherer (2003) more recently have noted that an important social dimension that may elicit discrete emotions includes the evaluation of justice or equity. From this perspective, these authors suggest that justice in itself may serve as an evaluative standard or appraisal that may shape emotional reactions in terms of form, valence, and intensity. Clearly, the role of discrete emotions in the psychology of justice needs to be taken into account.

It seems clear that justice researchers have to take responsibility to include emotional expressions of people's feelings (implicit, explicit, as a dependent or independent variable and so forth) into their empirical enterprises in order to further refine and deepen our understanding of the phenomenon that we refer to as social justice. In the present special issue we brought together a series of papers that address the relationship between feelings and justice in a variety of social settings. These authors all review relevant research focusing on the emotional basis of justice and the possible consequences of this relationship. Interestingly, although our authors approach this topic from different backgrounds (social psychology, management, economics, morality, and philosophy) they arrive at quite similar conclusions, namely that justice and emotions have to be seen as closely connected.

The first paper by Tripp, Bies, and Aquino focuses on how emotions play a role in determining actions as a result of injustice in the workplace. According to these authors, acts of injustice can also be repaired in a positive way (i.e., related to issues of reconciliation and forgiveness) rather than in negative ways, such as taking revenge. Moreover, this paper sheds a clear view on how managers should deal with injustice and possibly vengeful acts committed in the workplace. 
The second paper, by van Winden, discusses recent research in the field of economics addressing the role of emotions in interdependent negotiation situations. In doing this, the author reviews experimental findings on the "power-to-take" game and focuses on how fairness is defined and approached by economists as well as which emotions (e.g., shame, guilt) play a role in negotiations. This article also provides insightful information about how economists have looked at emotions in the past and how their current perspective seems to change (thereby promoting a useful collaboration between psychology and economics; see also De Cremer et al., 2006).

The third paper, by Stouten, De Cremer, and Van Dijk, focuses on the emotional and retributive implications of violations of coordination rules in symmetric public good dilemmas. The paper notes that research examining emotional and retributive reactions to violations of the equality rule by a fellow group member reveal that equality indeed is related to people's personal values and of what they consider to be fair. The paper further states that a violation of the equality rule results in emotional reactions, and these emotional experiences encourage further retributive actions. Furthermore, the authors describe the different reactions to equality violation as a function of three features: (1) motives to use equality, (2) attributions for explaining the violation, and (3) the honesty of the given explanation.

The fourth paper, by Opotow and McClelland, discusses hate from a variety of analytical and scientific viewpoints, including psychoanalytic, social psychological, and criminal justice literatures. Following these viewpoints the paper proposes a theory of hate that is interdisciplinary and spans levels of analysis. Their theoretical development has strong implications for how we may broaden our thinking about hate, and how we should study hate.

The fifth paper, by Haidt and Graham, focuses on the possibility that "morality opposes justice" and suggests that conservatives may have moral intuitions that liberals may not recognize. More specifically, the authors note that researchers in moral psychology and social justice have agreed that morality is about matters of harm, rights, and justice. As a result of this conceptualization of morality, conservative opposition to social justice programs has appeared to be immoral and has been explained as a product of various non-moral processes. Haidt and Graham argue, however, that the moral domain is usually much broader, encompassing many more aspects of social life and valuing traditional institutions as much or more than individual liberties. The authors go on to present theoretical and empirical reasons for believing that there are in fact five psychological systems that provide the foundations for the world's many moral codes. The five foundations are psychological preparations for caring about and reacting emotionally to harm, reciprocity (including justice, fairness, and rights), ingroup, hierarchy, and purity. According to Haidt and Graham, political liberals 
have moral intuitions primarily based upon the first two foundations, and therefore misunderstand the moral motivations of political conservatives, who generally rely upon all five foundations.

Taken together, the five articles included in this special issue on justice and feelings take different angles and very different perspectives. With this special issue we hope to have contributed to what, in addition to more process-oriented studies, is an important subject for future social justice research, namely the study of justice and feelings.

\section{ACKNOWLEDGEMENTS}

The preparation of this article was supported by a fellowship from the Netherlands Organization for Scientific Research (NWO) awarded to the first author (Grant No. 016-005.019) and a VICI innovational research grant from the same organization awarded to the second author (Grant No. 453.03.603).

\section{REFERENCES}

Adams, J. S. (1965). Inequity in social exchange. In Berkowitz, L. (ed.), Advances in Experimental Social Psychology, Vol. 2, Academic Press, New York, pp. 267-299.

Barclay, L. J., Skarlicki, D. P., and Pugh, S. D. (2005). Exploring the role of emotions in injustice perceptions and retaliation. J. Appl. Psychol., 90, 629-643.

Bies, R. J. (1987). The predicament of injustice: The management of moral outrage. In Cummings, L. L. and Staw, B. M. (eds.), Research in Organizational Behavior, Vol. 9, JAI Press, Greenwich, CT, pp. 289-319.

Bies, R. J., and Moag, J. S. (1986). Interactional justice: Communication criteria of fairness. In Lewicki, L. R., Bazerman, M. and Sheppard, B. (eds.), Research on Negotiation in Organizations, Vol. 1, JAI Press, Greenwich, CT, pp. 43-55.

Bies, R. J., and Tripp, T. M. (2002). "Hot flashes, open wounds": Injustice and the tyranny of its emotions. In Steiner, D. D., Skarlicki, D. P. and Gilliland, S. W. (eds.), Emerging Perspectives on Managing Organizational Justice, Information Age Publishing, Greenwich, Connecticut, pp. 203-221.

Brockner, J., and Wiesenfeld, B. M. (1996). An integrative framework for explaining reactions to decisions: Interactive effects of outcomes and procedures. Psychol. Bull., 120, 189-208.

Chebat, J.-C., and Slusarczyk, W. (2005). How emotions mediate the effects of perceived justice on loyalty in service recovery situations: an empirical study. J. Bus. Res., 58, 664-673.

Cosmides, L., and Tooby, J. (1992). Cognitive adaptations for social exchange. In Barkow, J. H., Cosmides, L. and Tooby, J. (eds.), The adapted mind: Evolutionary psychology and the generation of culture, Oxford University Press, New York, pp. 163-228.

Damasio, A. R. (1994). Descartes' error, New York: Grosset/Putnam.

De Cremer, D. (2006). Discrete emotions and procedural fairness effects on self-esteem: The role of certainty versus uncertainty-related emotions, the Netherlands: Unpublished manuscript, Tilburg University.

De Cremer, D. , and Tyler, T. R. (2005). Managing group behavior: The interplay between procedural justice, sense of self, and cooperation. In Zanna, M. (ed.), Advances in Experimental Social Psychology, Vol. 37, Academic Press, New York, NY, pp. 151-218.

De Cremer, D. , Zeelenberg, M., and Murnighan., J. K. (2006). Social Psychology and Economics, Mahwah, New Jersey: Lawrence Erlbaum. 
Ellsworth, P. C., and Scherer, K. R. (2003). Appraisal processes in emotion. In Davidson, R. J., Scherer, K. R. and Goldsmith, H. H. (eds.), Handbook of Affective Sciences, Oxford University Press, New York, pp. 572-595.

Finkel, N. J. (2001). Not fair! The Typology of Commonsense Unfairness, Washington, DC: American Psychological Association.

Folger, R. (1984). Preface. In Folger, R. (ed.), The Sense of Injustice: Social Psychological Perspectives, Plenum, New York, pp. ix-x.

Folger, R., and Cropanzano, R. (1998). Organizational Justice and Human Resource Management, Thousand Oaks, CA: Sage Publications, Inc.

Forgas, J. P. (2000). Feeling and Thinking: The Role of Affect and Social Cognition, Cambridge, UK: Cambridge University Press.

Frijda, N. (1993). Moods, emotion episodes, and emotions. In Lewis, M. and Haviland, I. M. (eds.), Handbook of Emotions, Guilford Press, New York, pp. 381-403.

Greenberg, J., and Colquitt, J. A. (2005). Handbook of Organizational Justice, Mahwah, New Jersey: Lawrence Erlbaum Associates.

Griffin, R. W., Leary-Kelly, O' A., and Collins, J. M. (1998). Dysfunctional Behavior in Organizations: Violent and Deviant Behavior: Part A, Stamford: JAI Press.

Haidt, J. (2001). The emotional dog and its rational tail: A social intuitionist approach to moral judgment. Psychol. Bull., 108, 814-834.

Homans, G. C. (1961). Social Behavior: Its Elementary Forms, New York: Harcourt, Brace, and World.

Hume, D. (1739/1992). Treatise of human nature, Buffalo, Prometheus Books.

Izard, C. E. (1993). Four systems for emotion activation: Cognitive and noncognitive processes. Psychol. Rev., 100, 68-90.

Kant, I. (1959). Foundations of the metaphysics of morals (L. W. Beck, translation), Indianapolis, IN: Bobbs-Me.

Larsen, R. J., Diener, E., and Lucas, R. E. (2002). Emotion: Models, measures, and individual differences. In Lord, R. G., Klimoski, R. J. and Kanfer, R. (eds.), Emotions In the Workplace, Jossey-Bass, San Fransisco, pp. 64-106.

Lerner, M. J. (2003). The justice motive: Where social psychologists found it, how they lost it, and why they may not find it again. Pers. Soc. Psychol. Rev., 7, 388-399.

Lerner, J. S., and Keltner, D. (2000). Beyond valence: Toward a model of emotion-specific influences on judgment and choice. Cognition and Emotion, 14, 473-493.

Lerner, J. S., Small, D. A., and Loewenstein, G. (2004). Heart strings and purse strings: Carryover effects of emotions and economic decisions. Psychol. Sci., 15, 337-341.

Lyons, W. (1999). The philosophy of cognition and emotion. In Dalgleish, T. and Pwer, M. J. (eds.), Handbook of Cognition and Emotion, John Wiley and Sons, Chichester, pp. 21-44.

Mikula, G., Scherer, K. R., and Athenstaedt, U. (1998). The role of injustice in the elicitation of differential emotional reactions. Pers. Soc. Psychol. Bull., 24, 769-783.

Miller, D. (1999). Principles of Social Justice, Cambridge, Massachusetts: Cambridge University Press.

Montada, L. (2003). Justice, equity, and fairness in human relations. In Millon, T., Lerner, M. J. and Weiner, I. B. (eds.), Handbook of Psychology: Personality and Social Psychology, Vol. 5, John Wiley \& Sons, New Jersey, pp. 537-568.

Rawls, J. (1971). A Theory of Justice, Cambridge Massachusetts: Harvard University Press.

Sinclair, R. C., and Mark, M. M. (1991). Mood and the endorsement of egalitarian macrojustice versus equity-based microjustice principles. Pers. Soc. Psychol. Bull., 17, 369-375.

Russell, J. A. (1980). A circumplex model of affect. J. Pers. Soc Psychol., 39, 1161-1178.

Sinclair, R. C., and Mark, M. M. (1992). The influence of mood state on judgment and action: Effects on persuasion, categorization, social justice, person perception, and judgmental accuracy. In Martin, L. and Tesser, A. (eds.), The Construction of Social Judgments, Erlbaum, Hillsdale, NJ, pp. 165-193.

Skarlicki, D. P., and Folger, R. (1997). Retaliation in the workplace: The roles of distributive, procedural, and interactional justice. J. Appl. Psychol., 82, 434-443.

Thibaut, J., and Walker, L. (1975). Procedural Justice: A psychological Analysis, Hillsdale, NJ: Erlbaum. 
Tyler, T. R., and Smith, H. J. (1998). Social justice and social movements. In Gilbert, D. T. and Fiske, S. T. (eds.), Handbook of Social Psychology, (4th ed. McGraw-Hill, New York, NY.

Van den Bos, K (2001). Fundamental research by means of laboratory experiments is essential for a better understanding of organizational justice. J. Vocat. Behav., 58, 254-259.

Van den Bos, K. (2003). On the subjective quality of social justice: The role of affect as information in the psychology of justice judgments. J. Pers. Soc. Psychol., 85, 482-498.

Van den Bos, K. , and Lind, E. A. (2002). Uncertainty management by means of fairness judgments. In Zanna, M. P. (ed.), Advances in Experimental Social Psychology, Vol. 34, Academic Press, Inc, San Diego, CA, pp. 1-60.

Watson, D. (2000). Mood and Temperament, New York: Guilford Press.

Weiss, H. M., and Cropanzano, R. (1996). An affective events approach to job satisfaction. In Staw, B. M. and Cummings, L. L. (eds.), Research in Organizational Behavior, Vol. 18, JAI Press, Greenwich, CT, pp. 1-47.

Weiss, H. M., Suckow, K., and Cropanzano, R. (1999). Effects of justice conditions on discrete emotions. J. Appl. Psychol., 84, 786-794. 